Research Paper

\title{
Alanine Aminotransferase Elevation during Peginter- feron Alpha-2a or Alpha-2b plus Ribavirin Treatment
}

\author{
Masato Nakamura ${ }^{1}$, Tatsuo Kanda1 ${ }^{1}{ }^{凶}$, Tatsuo Miyamura ${ }^{1}$, Shuang $\mathrm{Wu}^{1}$, Shingo Nakamoto ${ }^{1,2}$, Osamu Yo- \\ kosuka ${ }^{1}$ \\ 1. Department of Gastroenterology and Nephrology, Chiba University, Graduate School of Medicine, 1-8-1 Inohana, Chuo-ku, Chiba \\ 260-8670, Japan; \\ 2. Department of Molecular Virology, Chiba University, Graduate School of Medicine, 1-8-1 Inohana, Chuo-ku, Chiba 260-8670, Japan.
}

$\triangle$ Corresponding author: Tatsuo Kanda, M.D., Ph.D., Associate Professor, Department of Gastroenterology and Nephrology, Chiba University, Graduate School of Medicine, 1-8-1 Inohana, Chuo-ku, Chiba (260-8670), Japan. Tel.: +81-43-226-2086, Fax: +81-43-226-2088; Email: kandat-cib@umin.ac.jp.

( ) Ivyspring International Publisher. This is an open-access article distributed under the terms of the Creative Commons License (http://creativecommons.org/ licenses/by-nc-nd/3.0/). Reproduction is permitted for personal, noncommercial use, provided that the article is in whole, unmodified, and properly cited.

Received: 2013.04.04; Accepted: 2013.06.09; Published: 2013.06.15

\begin{abstract}
Alanine aminotransferase (ALT) elevation was occassionally observed during the treatment with combination peginterferon alpha plus ribavirin. Two forms of peginterferon are currently available as a standard of care with or without direct-acting antivirals against hepatitis $\mathrm{C}$ virus (HCV). Until the appearance of interferon-sparing regimen, peginterferon alpha plus ribavirin will play a central role in the eradication of HCV. In the present study, we compared ALT elevations in response to peginterferon alpha-2a plus ribavirin or peginterferon alpha-2b plus ribavirin in HCV genotype-I-infected patients. There were no significant differences in ALT elevations between treatments with the two peginterferons, but in a comparison of the proportions of patients with transient ALT elevation from baseline between the two groups, transient ALT elevation was observed more in sustained virological response (SVR) patients treated with peginterferon alpha-2a than with peginterferon alpha-2b. However, no patients discontinued treatment due to ALT elevation. Patients with transient ALT elevation from baseline during the treatment had less favorable IL28B rs80999 17 genotype in the peginterferon alpha-2b group. Patients achieving SVR tended to have lower ALT levels, although some had persistent ALT elevation during treatment. In conclusion, clinicians should pay attention to possible ALT elevation during the treatment of chronic hepatitis $C$ patients.
\end{abstract}

Key words: ALT, HCV, IL28B, Peginterferon, Ribavirin.

\section{INTRODUCTION}

Peginterferon alpha-2a or peginterferon alpha- $2 \mathrm{~b}$ plus ribavirin has been the current standard of care treatment for chronic hepatitis C [1-3]. Even after the appearance of the new standard of care, telaprevirand boceprevir-including regimens, peginterferon plus ribavirin will still be needed to eradicate hepatitis $\mathrm{C}$ virus $(\mathrm{HCV})$ until interferon-sparing regimens finally become available [4-8]. Peginterferon alpha-2a is a subcutaneous formulation of interferon alpha-2a, produced by its attachment to a $40-\mathrm{kDa}$ branched polyethylene glycol moiety by a stable amid bond [9]. A semi-synthetic form of interferon alpha- $2 b$, by attaching to a $12-\mathrm{kDa}$ mono-methoxy polyethylene glycol, has been developed as peginterferon alpha-2b, which fulfills the requirements of a long-acting interferon alpha protein while providing significant clinical benefits [10].

Elevations of alanine aminotransferase (ALT) levels were occasionally observed while interferon alpha or peginterferon alpha was administered to 
HCV-infected patients [11-15]. HCV infection is persistent in the majority of instances in the face of a humoral and cellular immune response [16]. Previous studies suggested that cytotoxic $\mathrm{T}$ lymphocytes as well as antibodies to viral epitope, crucial in the eradication of virus-infected hepatocytes, cannot completely eliminate $\mathrm{HCV}$ and may contribute to chronic liver injury. It is possible that some changes in ALT levels were dependent on this HCV pathogenesis $[12,14]$. ALT elevation was also reported as one of the side effects of interferon alpha [18]. Chronic hepatitis C sometimes presents features such as autoimmune hepatitis [19], and there are several reports of interferon inducing autoimmune liver diseases and causing ALT elevation in chronic hepatitis C patients $[11,13,15]$. Thus, ALT elevation is often observed during the treatment of chronic hepatitis $\mathrm{C}$ and occasionally leads to life-threatening disease [20-22].

Peginterferon alpha is currently available in two forms: peginterferon alpha-2a and peginterferon alpha-2b. Thus, in the present study, we designed a retrospective study to compare ALT elevations in response to peginterferon alpha-2a plus ribavirin or peginterferon alpha- $2 \mathrm{~b}$ plus ribavirin in $\mathrm{HCV}$ genotype-1-infected patients. We also determined IL28B rs8099917 and investigated its effects on ALT eleva- tion.

\section{MATERIALS AND METHODS}

\section{Patients}

Chronic hepatitis C patients with genotype 1 who visited Chiba University School of Medicine Hospital between August 2004 and June 2012 and were treated with peginterferon alpha plus ribavirin were consecutively included and analyzed in this study. Of them, 41 and 60 patients were treated with peginterferon alpha- $2 a$ and alpha- $2 b$, respectively (Table 1). Patients were eligible if they met the following inclusion criteria: (1) infected with HCV genotype 1, (2) age $\geq 20$ years, (3) diagnosed as chronic hepatitis $C$, (4) no pregnancy, (5) no severe heart disease, (6) no abnormal hemoglobinemia, (7) no chronic renal failure, (8) no mental disorder, (9) no severe hepatic failure, (10) no autoimmune disorder, (11) no drug allergy for interferon or for nucleos(t)ide analogues including ribavirin, (12) no current intravenous drug abuse, and (13) no HIV infection [23,24]. The study protocol was approved by the Ethics Committee of Chiba University School of Medicine (No.1462) and conformed to the ethical guidelines of the 1975 Declaration of Helsinki.

Table I. Baseline characteristics of patients in the present study.

\begin{tabular}{|c|c|c|c|c|}
\hline & Total patients & PegIFN alpha-2a & PegIFN alpha-2b & P-values \\
\hline Number of patients & 101 & 41 & 60 & \\
\hline Age (years) & $54.7 \pm 11.3$ & $52.9 \pm 11.8$ & $56.2 \pm 10.8$ & NS \\
\hline Gender (male/female) & $52 / 49$ & $21 / 20$ & $31 / 29$ & NS \\
\hline Body mass index $\left(\mathrm{kg} / \mathrm{m}^{2}\right)$ & $23.0 \pm 3.6$ & $22.6 \pm 3.7$ & $23.3 \pm 3.5$ & NS \\
\hline IL28B, major/minor & $67 / 34$ & $30 / 11$ & $37 / 23$ & NS \\
\hline HCV viral load (high/low) & $100 / 1$ & $41 / 0$ & $59 / 1$ & NS \\
\hline AST (IU/L) & $59.8+52.8$ & $59.4 \pm 47.7$ & $60.1 \pm 56.1$ & NS \\
\hline $\operatorname{ALT}(\mathrm{IU} / \mathrm{L})$ & $71.5 \pm 67.5$ & $71.7 \pm 65.6$ & $71.4 \pm 69.1$ & NS \\
\hline$\gamma$-GTP (IU/L) & $60.7 \pm 79.3$ & $67.9 \pm 96.0$ & $55.3 \pm 65.4$ & NS \\
\hline Hemoglobin (g/dL) & $14.1 \pm 1.1$ & $14.0 \pm 1.1$ & $14.1 \pm 1.1$ & NS \\
\hline Platelet $\left(\times 10^{4} / \mu \mathrm{L}\right)$ & $19.2 \pm 23.3$ & $17.5 \pm 4.8$ & $20.2 \pm 30.0$ & NS \\
\hline $\mathrm{AFP}(\mathrm{ng} / \mathrm{mL})$ & $9.2 \pm 8.8$ & $10.0 \pm 11.1$ & $8.6 \pm 6.7$ & NS \\
\hline HbA1c (\%) & $5.1 \pm 0.54$ & $5.2 \pm 0.69$ & $5.1 \pm 0.31$ & NS \\
\hline Total cholesterol (mg/dL) & $178 \pm 30.4$ & $184 \pm 26.8$ & $174 \pm 32.1$ & NS \\
\hline Treatment-naive (\%) & $72(71.2)$ & $30(73.1)$ & $42(70)$ & NS \\
\hline Adherence, good/poor & $75 / 26$ & $32 / 9$ & $43 / 17$ & NS \\
\hline $\operatorname{RVR}(\%)$ & $12(11.8)$ & $9(21.9)$ & $3(5)$ & 0.023 \\
\hline $\operatorname{EVR}(\%)$ & $50(49.5)$ & $23(56.0)$ & $27(45.0)$ & NS \\
\hline SVR (\%) & $50(49.5)$ & $20(48.7)$ & $30(50.0)$ & NS \\
\hline
\end{tabular}

IL28B, IL28Brs8099917; Adherence was evaluated by 80/80/80 ( $>80 \%$ of PegIFN dose, $>80 \%$ of ribavirin dose, $>80 \%$ treatment duration) [28]. Adherence good: 80/80/80 (+) ; adherence poor: 80/80/80 (-); RVR, rapid virological response; EVR, early virological response; SVR, sustained virological response; NS, not statistically significant difference. 


\section{Treatment and definition of virological response}

Peginterferon alpha-2b (Peg-intron; MSD, Tokyo, Japan) was administered as a once-weekly dose of $1.5 \mu \mathrm{g} / \mathrm{kg}$ (weight-based dosing). Peginterferon alpha-2a (Pegasys; Chugai Pharmaceutical CO., LTD, Tokyo, Japan) was used as a once-weekly dose of $180 \mu \mathrm{g}$. Ribavirin was administered according to weight-based dosing (600 $\mathrm{mg}$ for patients $\leq 60 \mathrm{~kg}, 800 \mathrm{mg}$ for patients weighing 60 to $80 \mathrm{~kg}$, and $1,000 \mathrm{mg}$ for patients $>80 \mathrm{~kg}$ ). Patients received 48 weeks of treatment with either peginterferon alpha-2a plus ribavirin (Copegus; Chugai Pharmaceutical CO., LTD, Tokyo, Japan) or 48 weeks of treatment with peginterferon alpha-2b plus ribavirin (Rebetol; MSD, Tokyo, Japan).

Clinical and laboratory assessments were performed at 4, 12, 24 and 48 weeks after the commencement of therapy and after the 24-week follow-up period. Adverse reactions were investigated by patient interviews, physical examinations and laboratory tests. Patients with negative HCV RNA within the initial 4 weeks of treatment were considered to have had rapid virological response (RVR). Patients who had negative HCV RNA within the initial 12 weeks of treatment were considered to have had complete early virological response (cEVR) (described as EVR in this article). Sustained virological response (SVR) was defined as negative serum HCV RNA at 24 weeks after the end of treatment $[6,23]$.

\section{Measurement of HCV RNA in plasma and laboratory tests}

HCV RNA was measured by COBAS TaqMan $\mathrm{HCV}$ test (Roche Diagnostics, Tokyo, Japan) (range 1.2-7.8 $\log \mathrm{IU} / \mathrm{mL}$ ). A qualitative result below the lower limit of quantification was also determined as being either positive or negative [23]. HCV serotype was examined by serological genotyping assay [25]. Measurement of serum HCV RNA, serum ALT levels (range 8-42 IU/L), and other biochemical tests were carried out by standard methods every 4 weeks before, during the treatment, and for at least 24 weeks after the end of treatment.

\section{DNA extraction and TaqMan SNP assay for IL28B rs80999I 7}

To prepare DNA samples from blood cells, we used DNA Extract All Lysis Reagents (Applied Biosystems Inc., Foster City, CA, USA). A specific TaqMan genotyping assay was performed for rs8099917. Primers were manufactured by Applied Biosystems. Thermal cycling was performed with the ABI Step
One real-time PCR system according to the manufacturer's protocol. Activation of TaqMan GTXpress Master Mix (Applied Biosystems) and the initial denaturation cycle was at $95^{\circ} \mathrm{C}$ for 20 seconds, followed by 40 cycles at $95^{\circ} \mathrm{C}$ for 3 seconds and $60^{\circ} \mathrm{C}$ for 20 seconds. We analyzed IL28B rs8099917 TT as major type and TG/GG as minor type in the present study [26, 27]. The study protocol for IL28B analysis was approved the Ethics Committee of Chiba University School of Medicine (No.282/333).

\section{Statistical analysis}

Data are expressed as mean \pm standard deviation (SD). Differences were evaluated by Student's t-test or chi-square test. $P<0.05$ was considered statistically significant.

\section{RESULTS}

\section{Baseline characteristics}

One hundred one patients infected with $\mathrm{HCV}$ genotype 1 were enrolled in the present study. Baseline characteristics of the patients are shown in Table 1. All patients were Japanese, and had a median age of 54.7 years (range: 20 - 72); 52 (51.4\%) patients were men. Patients over 64 years of age accounted for 19 of 101 (18.8\%). IL28B rs8099917TT, TG and GG, respectively, were 30,11 and 0 in the peginterferon alpha-2a group, and 37, 21 and 2 in the peginterferon alpha- $2 \mathrm{~b}$ group [not statistically significant difference (NS)]. There were no differences in patient characteristics between the peginterferon alpha-2a and peginterferon alpha- $2 \mathrm{~b}$ groups. Eleven and 18, respectively, were re-treated patients in the peginterferon alpha-2a and peginterferon alpha- $2 b$ groups. Of the $11(26.8 \%)$ retreated patients in the peginterferon alpha-2a group, 7, 3 and 1 were relapse, null and unknown of previous response. Of the 18 $(30.0 \%)$ retreated patients in the peginterferon alpha- $2 \mathrm{~b}$ group, 3, 10 and 5 were relapse, null and unknown of previous response. Only one patient in the peginterferon alpha- $2 \mathrm{~b}$ group had lower than 5 $\log$ IU/mL of HCV RNA at baseline (Table 1).

\section{Virological response}

Adherence 80/80/80 [28], EVR, and SVR were not different between the two groups (Table 1). However, RVR was achieved in 41 patients of the peginterferon alpha-2a group $(21.9 \%)$ higher than that in the 60 patients of the peginterferon alpha- $2 \mathrm{~b}$ group $(5.0 \%)(P=0.023)$. As for these results, 20 and 30 of the patients, respectively, achieved SVR in the peginterferon alpha-2a and peginterferon alpha- $2 b$ groups; 11 and 16 were relapsers, and 5 and 19 were 
null responders.

\section{Abnormal ALT levels during treatment}

Next, we compared ALT changes between the treatments in the peginterferon alpha-2a $(\mathrm{n}=41)$ and peginterferon alpha- $2 \mathrm{~b}$ groups $(n=60)$ (Figure 1$)$. There were no differences in ALT levels between the combination treatments in the peginterferon alpha-2a and peginterferon alpha- $2 \mathrm{~b}$ groups (Figure 1A). Compared to each of the ALT levels at baseline, the proportions of patients with transient ALT elevation were $13(31.7 \%)$ and $12(20.0 \%)$ during treatment with peginterferon alpha-2a and peginterferon alpha- $2 b$, respectively. No patients discontinued treatment due to ALT elevation. Concerning the distribution of ALT elevation, 10 and 9, 0 and 1, 0 and 2, 2 and 0 , and 1 and 0 patients in the peginterferon alpha- $2 \mathrm{a}$ and peginterferon alpha- $2 \mathrm{~b}$ groups, respectively, were classified into $\leq$ 2-fold, $2 \sim \leq 3$-fold, $3 \sim \leq 4$-fold, $4 \sim \leq 5$-fold, and more than 5-fold of ALT at the upper limit of normal range. When severe ALT elevation was defined as more than 3-fold of the upper limit of the normal range of ALT, severe ALT elevation was observed in $3(7.3 \%)$ and $2(3.3 \%)$ of the peginterferon alpha-2a and peginterferon alpha- $2 \mathrm{~b}$ groups, respectively. There were no significant differences in ALT levels of SVR patients between the combination treatments in the peginterferon alpha- $2 \mathrm{a}(\mathrm{n}=20)$ and peginterferon alpha- $2 \mathrm{~b}$ groups $(\mathrm{n}=30)$ (Figure $1 \mathrm{~B})$. The proportions of SVR patients with transient ALT elevation were $7(35.0 \%)$ and $2(6.6 \%)$ during treatment with peginterferon alpha-2a and peginterferon alpha- $2 \mathrm{~b}$, respectively $(P=0.029)$. Transient ALT elevation was observed more in SVR patients treated with peginterferon alpha-2a than in those with peginterferon alpha- $2 \mathrm{~b}$. There were no significant differences in ALT levels of null-response patients between the combination treatments in the peginterferon alpha-2a $(\mathrm{n}=5)$ and peginterferon alpha- $2 \mathrm{~b}$ groups $(n=19)$ (Figure $1 C)$. The proportions of null-response patients with transient ALT elevation were in $2(40 \%)$ and $9(47.3 \%)$ during treatment with peginterferon alpha-2a and peginterferon alpha- $2 b$, respectively (NS).
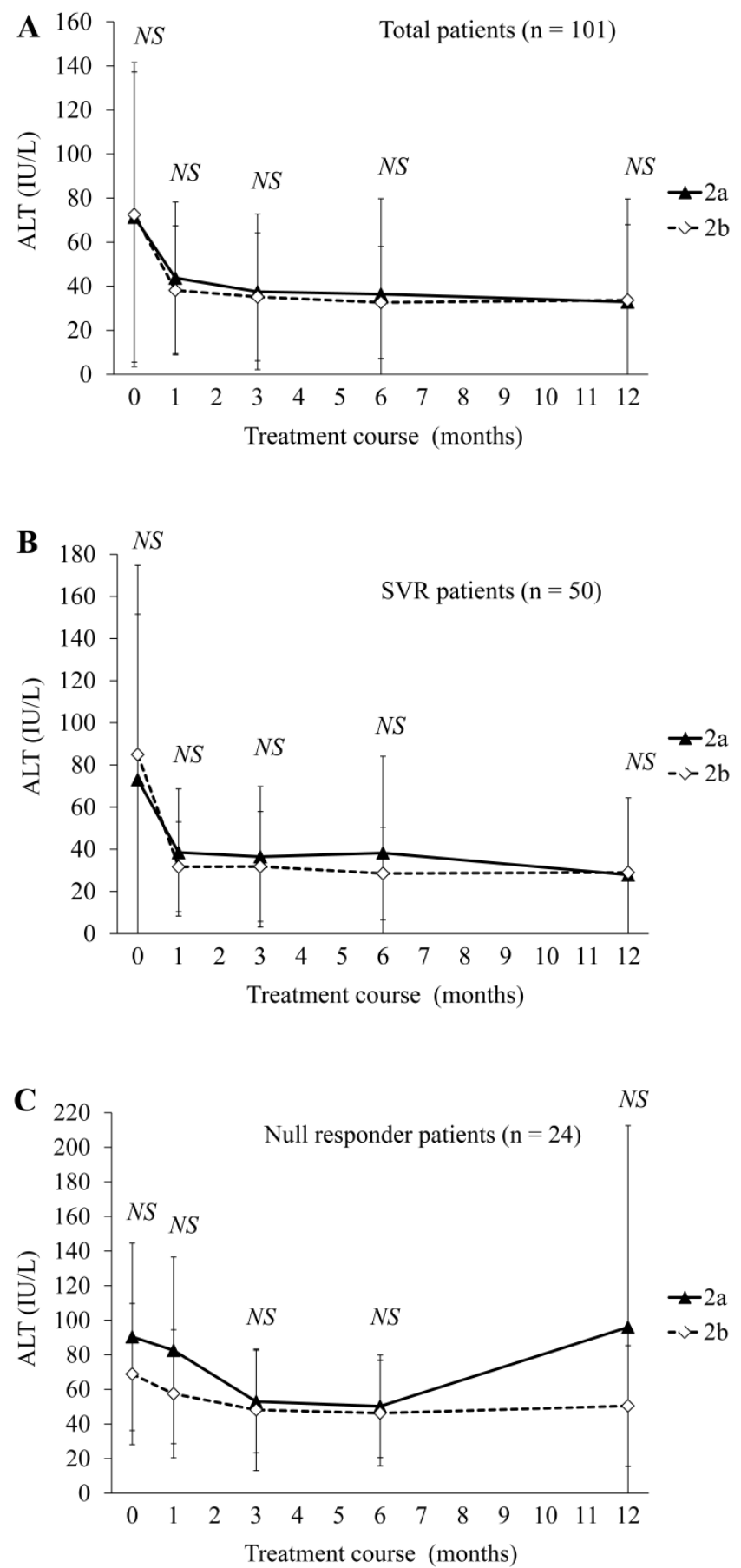

Fig I. ALT changes during peginterferon alpha plus ribavirin treatment for chronic hepatitis $C$ : comparison of patients treated with peginterferon alpha-2a plus ribavirin or peginterferon alpha-2b plus ribavirin. (A) Total patients $(n=\mid 0 I)$. Black triangles and white diamonds indicate patients treated with peginterferon alpha-2a plus ribavirin $(n=4 I)$ or peginterferon alpha-2b plus ribavirin $(n=60)$. (B) SVR patients $(n=50)$. Black triangles and white diamonds indicate patients treated with peginterferon alpha-2a plus ribavirin $(n=20)$ or peginterferon alpha-2b plus ribavirin $(n=30)$. (C) Null responder patients $(n=24)$. Black triangles and white diamonds indicate patients treated with peginterferon alpha-2a plus ribavirin $(n=5)$ or peginterferon alpha- $2 b$ plus ribavirin $(n=19)$. NS, no significant difference between two groups by Student's $t$-test. 
The impact of IL28B rs80999 I 7 genotypes on transient ALT elevation from baseline during the treatment

There have been several reports on the association between IL28B genotypes and ALT levels in chronic hepatitis C patients [29-31]. Next, we examined whether IL28B genotypes had an impact on ALT elevation from baseline in response to peginterferon alpha-2a plus ribavirin or peginterferon alpha- $2 b$ plus ribavirin in $\mathrm{HCV}$ genotype-1-infected patients. In the total patients $(n=101)$, those with transient ALT elevation during the treatment had less favorable IL28B rs8099917 genotype (major/minor: 11/14) than those without transient ALT elevation during the treatment (major/minor: 56/20; $P=0.013$ ). In the peginterferon alpha-2a group $(n=41)$, there were no differences in the distributions of IL28B rs8099917 genotypes between patients with and without transient ALT elevation during the treatment (major/minor: $8 / 5$ and $22 / 6$; NS). However, in the peginterferon alpha- $2 \mathrm{~b}$ group $(n=60)$, patients with transient ALT elevation during the treatment had less favorable IL28B rs8099917 genotype (major/minor: 3/9) than those without transient ALT elevation (major/minor: 34/14; $P=0.0096)$. Three and two patients with severe ALT elevation during the treatment had IL28B rs8099917 (major/minor: $1 / 2$ in the peginterferon alpha-2a group and $1 / 1$ in the peginterferon alpha- $2 \mathrm{~b}$ group, respectively).

\section{Patients achieving SVR tended to have lower ALT levels than patients with null response}

Next, we compared ALT changes between the treatments of 50 SVR patients and 24 null-response patients (Figure 2A). ALT levels were significantly lower at 4, 12 and 48 weeks in SVR patients than in the null responders. At 24 weeks, ALT levels also tended to be lower in SVR patients than in null responders. In the comparison of 20 SVR patients with 5 null-response patients treated with combination peginterferon alpha-2a plus ribavirin, ALT levels were significantly lower at 4 and 48 weeks in the SVR patients than in null responders (Figure 2B). In this treatment group, ALT levels tended to be lower at 12 and 24 weeks in the SVR patients than in null responders. In the comparison of 30 SVR patients with 19 null-response patients treated with combination peginterferon alpha-2b plus ribavirin, ALT levels were significantly lower from 4 to 48 weeks in the SVR patients than in null responders (Figure 2C). We showed that the ALT levels were significantly lower in SVR than in null-response patients, but this seems to be a natural consequence.
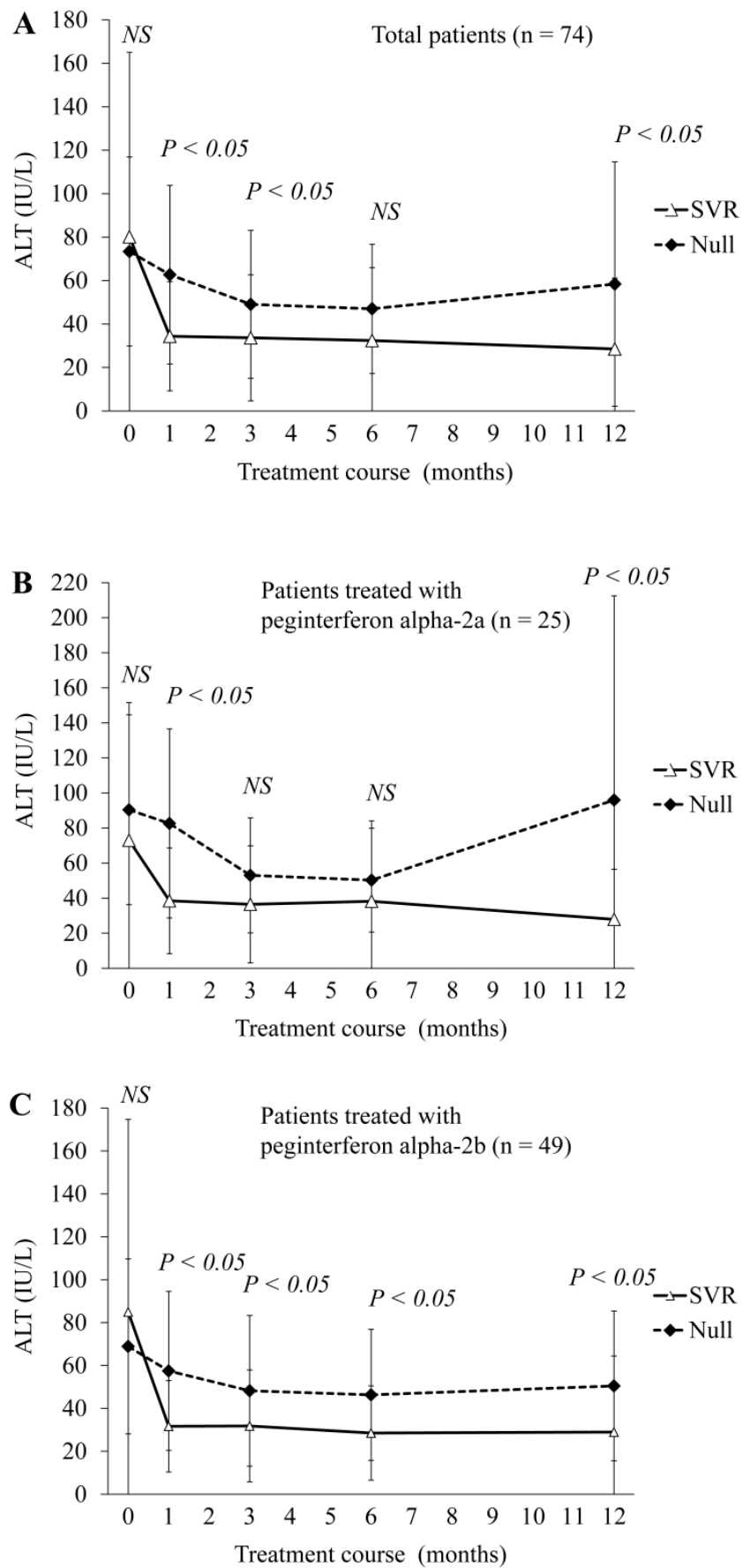

Fig 2. ALT changes during peginterferon alpha plus ribavirin treatment for chronic hepatitis C: comparison of SVR patients with null responders. (A) Total patients $(n=74)$. White triangles and black diamonds indicate SVR-achieving patients $(n=50)$ and null responders $(n=24)$, respectively. (B) Patients treated with peginterferon alpha-2a plus ribavirin $(n=25)$. White triangles and black diamonds indicate SVR-achieving patients $(\mathrm{n}=$ 20 ) and null responders $(n=5)$, respectively. (C) Patients treated with peginterferon alpha- $2 b$ plus ribavirin $(n=49)$. White triangles and black diamonds indicate SVR-achieving patients $(n=30)$ and null responders $(n=$ 19), respectively. $P$-value, significant difference between two groups by Student's $t$-test. NS, no significant difference. 


\section{ALT normalization was observed in 4 of 5 SVR-achieved patients with persistent ALT elevation during treatment}

In 5 of 50 SVR-achieved patients, ALT elevation was persistently observed during the treatment. Two and 3 patients with persistent ALT elevation during the treatment were observed among 20 peginterferon alpha-2a and 30 peginterferon alpha-2b-treated patients, respectively. Of interest, in 4 of these 5 patients, ALT normalization was observed, but only one peginterferon alpha-2b-treated patient had prolonged ALT elevation 12 months after stopping the treatment.

\section{DISCUSSION}

This retrospective analysis indicates that there were no significant differences in ALT elevations between treatments with peginterferon alpha-2a plus ribavirin and peginterferon alpha- $2 b$ plus ribavirin. When we compared the proportions of patients with transient ALT elevation from baseline between the two groups, transient ALT elevation was observed more in SVR patients treated with peginterferon alpha-2a than in those with peginterferon alpha-2b. In spite of these ALT elevation, no patients discontinued treatment. In the peginterferon alpha- $2 b$ group, patients with transient ALT elevation from baseline during the treatment had less favorable IL28B rs8099917 genotype. Patients achieving SVR tended to have lower ALT levels than null-responding patients, which seems to be a natural consequence. We also found that 5 patients achieving SVR had ALT elevation during the treatment, and in 4 of them, ALT returned to normal limits within 12 months after stopping treatment.

There have been several reports that the two peginterferons showed comparable anti-HCV activities [32-34], although there were also several controversial reports [35-38]. There is insufficient evidence in terms of any differences regarding adverse events [38]. Although the study number was small, our results support the previous studies [32-34], and there were no differences in ALT elevation between the two peginterferons. However, we found that the proportion of RVR patients was higher in the peginterferon alpha-2a-treatment group (Table 1).

Recently, several reports on genetic variation in IL28B have predicted peginterferon alpha and ribavirin treatment-induced HCV clearance [26, 27, 39-42]. Two studies reported that IL28B rs12979860 CC genotype was associated with higher ALT $[29,31]$. But Nunnari et al. [30] reported that the distribution of IL28B rs12979860 CC genotype did not differ between persistently normal ALT and hyper-ALT groups. In the present study, we found that patients with transient ALT elevation during the treatment had less favorable IL28B rs8099917 genotype when treated with peginterferon alpha- $2 \mathrm{~b}$.

Aoki et al. [43] reported that mean ALT values were significantly higher at certain time points during treatment with peginterferon alpha-2a plus ribavirin than those with peginterferon alpha- $2 b$ plus ribavirin. Therefore, attention should be paid to treated patients to avoid potentially severe adverse events such as acute exacerbation or liver failure [12, 22-25]. As HCV itself rarely causes severe liver injury [44, 45], peginterferon and/or ribavirin, or autoimmune mechanisms induced by such drugs, might lead to these phenomena and result in such as the reported severe liver injuries [22-25].

In conclusion, we observed no significant differences in ALT elevations between the two groups. However, comparing the proportions of patients with transient ALT elevation from baseline between the two groups, more transient ALT elevation was seen in SVR patients treated with peginterferon alpha-2a than with peginterferon alpha- $2 b$. None discontinued treatment due to the ALT elevation. Nevertheless, some SVR patients showed persistent ALT elevation during treatment. Although ALT levels returned to normal limits after treatment completion in most cases, clinicians should be aware of possible ALT elevation during the treatment of chronic hepatitis $C$ patients.

\section{ACKNOWLEDGEMENTS}

We are all thankful to our colleagues at the liver unit of our hospitals who cared for the patients described herein.

\section{Funding}

This work was supported by grants for Scientific Research from the Ministry of Education, Culture, Sports, Science, and Technology, Japan (TK), and grants from the Ministry of Health, Labour and Welfare of Japan (TK and OY).

\section{Contributors}

MN and TK designed the study. TK, TM, and OY saw the patients. MN, TK, TM, WS, and SN analyzed the data. MN and TK drafted the paper and all authors approved the paper.

\section{CONFLICT OF INTEREST}

Dr. Tatsuo Kanda reports receiving lecture fees from Chugai Pharmaceutical, MSD, Ajinomoto, and GlaxoSmithKline, and Prof. Osamu Yokosuka reports receiving grant support from Chugai Pharmaceutical, 
Bayer, MSD, Daiichi-Sankyo, Mitsubishi Tanabe Pharma, and Bristol-Myers Squibb.

\section{References}

1. Fried MW, Shiffman ML, Reddy KR, et al. Peginterferon alfa-2a plus ribavirin for chronic hepatitis C virus infection. N Engl J Med. 2002; 347: 975-982.

2. Muir AJ, Bornstein JD, Killenberg PG, et al. Peginterferon alfa-2b and ribavirin for the treatment of chronic hepatitis $\mathrm{C}$ in blacks and non-Hispanic whites. N Engl J Med. 2004; 350: 2265-2271.

3. Kanda T, Imazeki F, Yokosuka O. New antiviral therapies for chronic hepatitis C. Hepatol Int. 2010; 4: 548-561.

4. Ghany MG, Strader DB, Thomas DL, Seeff LB. Diagnosis, management, and treatment of hepatitis C: an update. Hepatology. 2009; 49: 1335-1374.

5. European Association for the Study of the Liver. EASL clinical practice guidelines: management of hepatitis C virus infection. J Hepatol. 2011; 55: 245-264

6. Omata M, Kanda T, Yu ML, et al. APASL consensus statements and management algorithms for hepatitis $\mathrm{C}$ virus infection. Hepatol Int. 2012; 55: 409-435.

7. Kumada $\mathrm{H}$, Toyoda J, Okanoue $\mathrm{T}$, et al. Telaprevir with peginterferon and ribavirin for treatment-naive patients chronically infected with $\mathrm{HCV}$ of genotype 1 in Japan. J Hepatol. 2012; 56: 78-84.

8. Suzuki Y, Ikeda K, Suzuki F, et al. Dual oral therapy with daclatasvir and asunaprevir for patients with HCV genotype $1 \mathrm{~b}$ infection and limited treatment options. J Hepatol. 2012 [Epub ahead of print].

9. Hadziyannis SJ, Papatheodoridis GV. Peginterferon-alpha2a (40kDa) for chronic hepatitis C. Expert Opin Pharmacother. 2003; 4: 541-551.

10. Wang YS, Youngster S, Grace M, et al. Structural and biological characterization of pegylated recombinant interferon alpha- $2 b$ and its therapeutic implications. Adv Drug Deliv Rev. 2002; 54: 547-70.

11. Silva MO, Reddy KR, Jeffers LJ, et al. Interferon-induced chronic active hepatitis? Gastroenterology. 1991; 101(3): 840-842.

12. Sindo M, Di Bisceglie AM, Hoofnagle JH. Acute exacerbation of liver disease during interferon alfa therapy for chronic hepatitis C. Gastroenterology. 1992; 102(4 Pt 1): 1406-1408.

13. Garcia-Buey L, Garcia-Monzon C, Rodriguez S, et al. Latent autoimmune hepatitis triggered during interferon therapy in patients with chronic hepatitis C. Gastroenterology. 1995; 108: 1770-1777.

14. Cervoni JP, Degos F, Marcellin P, et al. Acute hepatitis induced a-interferon, associated with viral clearance, in chronic hepatitis C. J Hepatol. 1997; 17: 1113-1116.

15. Lorke J, Erhardt A, Haussinger D. Induction of autoinnune hepatitis by pegylated interferon alfa-2b in chronic hepatitis C. Clin Gastroenterol Hepatol. 2004; 2: xx.

16. Chang KM, Rehermann B, Chisari FV. Immunopathology of hepatitis C. Springer Semin Immunopathol. 1997; 19: 57-68

17. Meyer K, Ait-Goughoulte M, Keck ZY, Foung S, Ray R. Antibody-dependent enhancement of hepatitis $\mathrm{C}$ virus infection. J Virol. 2008; 82: 2140-2149.

18. Fattovich G, Giustina G, Favarato S, et al. A survey of adverse events in 11241 patients with chronic viral hepatitis treated with alfa interferon. J Hepatol. 1996; 24: 38-47.

19. Mishiro S, Takeda K, Hoshi Y, et al. An autoantibody cross-reactive to hepatitis $\mathrm{C}$ virus core and a host nuclear antigen. Autoimmunity. 1991; 10: $269-273$

20. Kogre T, Ueno Y, Fukushima K, et al. Fulminant hepatic failure in a case of autoimmune hepatitis in hepatitis $C$ during peg-interferon-alpha $2 b$ plus ribavirin treatment. World J Gastroenterol. 2007;13: 4394-4397.

21. Kato $H$, Ikeuchi $H$, Nakamura M. Acute exacerbation of liver disease induced by peglated interferon alpha2a treatment for chronic hepatitis $\mathrm{C}$. International Journal of Clinical Medicine. 2010; 1: 1-5

22. Yasui S, Fujiwara K, Yokosuka O. Autoimmune fulminant hepatic failure in chronic hepatitis $C$ during peg-interferon-alpha $2 b$ plus ribavirin treatment showing histological heterogeneity. Dig Liver Dis. 2011; 43: 666-667.

23. Kanda T, Imazeki F, Yonemitsu Y, et al. Quantification of hepatitis C virus in patients treated with peginterferon-alfa 2a plus ribavirin treatment by COBAS TaqMan HCV test. J Viral Hepat. 2011; 18: q292-297.

24. Miyauchi T, Kanda T, Imazeki F, et al. Response to peginterferon-alpha $2 \mathrm{~b}$ and ribavirin in Japanese patients with chronic hepatitis $\mathrm{C}$ genotype 1 . Hepatol Int. 2013; 7: 144-152.

25. Tanaka T, Tsukiyama-Kohara K, Yamaguchi K, et al. Significance of specific antibody assay for genotyping of hepatitis $C$ virus. Hepatology. 1994; 19: 1347-1353.
26. Miyamura T, Kanda T, Nakamoto S, et al. Hepatic STAT1-nuclear translocation and interleukin 28B polymorphisms predict treatment outcomes in hepatitis C virus genotype 1-infected patients. PloS One. 2011; 6: e28617

27. Miyamura T, Kanda T, Nakamoto $S$, et al. Roles of ITPA and IL28B genotypes in chronic hepatitis $C$ patients treated with peginterferon plus ribavirin. Viruses. 2012; 4: 1264-1278.

28. McHutchison JG, Manns M, Patel K, et al. Adherence to combination therapy enhances sustained response in genotype-1-infected patients with chronic hepatitis C. Gastroenterology. 2002; 123: 1061-1069.

29. Agundez JA, Garcia-Martin E, Maestro ML, et al. Relation of IL28B gene polymorphism with biochemical and histological features in hepatitis C virus-induced liver disease. PloS One. 2012; 7: e37998.

30. Nunnari G, Pinzone MR, Cacopardo B. Lack of clinical and histological progression of chronic hepatitis $C$ in individuals with true persistently normal ALT: the result of a 17-year follow-up. J Viral Hepat. 2013; 20: e131-e137.

31. Noureddin M, Wright EC, Alter H, et al. Association of IL28B genotype with fibrosis progression and clinical outcomes in patients with chronic hepatitis C: A longitudinal analysis. Hepatology. 2013; [Epub ahead of print].

32. Di Bisceglie AM, Ghalib RH, Hamzeh FM, Rustgi VH. Early virologic response after peginterferon alpha-2a plus ribavirin or peginterferon alpha-2b plus ribavirin treatment in patients with chronic hepatitis C. J Viral Hepat. 2007; 14: 721-729.

33. Laguno M, Cifuentes C, Murillas J, et al. Randomized trial comparing pegylated interferon alpha- $2 \mathrm{~b}$ versus pegylated interferon alpha-2a, both plus ribavirin, to treat chronic hepatitis $\mathrm{C}$ in human immunodeficiency virus patients. Hepatology. 2009; 49: 22-31.

34. McHutchison JG, Lawitz EJ, Shiffman ML, et al. Peginterferon alfa-2b or alfa-2a with ribavirin for treatment of hepatitis C infection. N Engl J Med. 2009; 361: 580-593.

35. Rumi MG, Aqhemo A, Prati GM, et al. Randomized study of peginterferon-alpha2a plus ribavirin vs peginterferon-alpha2b plus ribavirin in chronic hepatitis C. Gastroenterology. 2010; 138: 108-115.

36. Ascione A, De Luca M, Tartaglione MT, et al. Peginterferon alfa-2a plus ribavirin is more effective than peginterferon alfa- $2 b$ plus ribavirin for treating chronic hepatitis C virus infection. Gastroenterology. 2010; 138: 116-122.

37. Witthoeft T, Hueppe D, John C, et al. Efficacy and tolerability of peginterferon alfa-2a or alfa-2b plus ribavirin in the daily routine treatment of patients with chronic hepatitis C in Germany: The PRACTICE study. J Viral Hepat. 2010; 17:459-468.

38. Award T, Thorlund K, Hauser G, et al. Peginterferon alpha-2a is associated with higher sustained virological response than peginterferon alfa-2b in chronic hepatitis $C$ : systemic review of randomized trials. Hepatology. 2010; 51: 1176-1184.

39. Ge D, Fellay J, Thompson AJ, et al. Genetic variation in IL28B predicts hepatitis C treatment-induced viral clearance. Nature. 2009; 461: 399-401.

40. Tanaka Y, Nishida N, Sugiyama M, et al. Genome-wide asssociation of IL28B with response to pegylated interferon-alpha and ribavirin therapy for chronic hepatitis C. Nat Genet. 2009; 41: 1105-1109.

41. Suppiah V, Moldovan M, Ahlenstiel G, et al. IL28B is associated with response to chronic hepatitis $C$ interferon-alpha and ribavirin therapy. Nat Genet. 2009; 41: 1100-1104

42. Nakamoto S, Kanda T, Imazeki F, et al. Simple assay based on restriction fragment length polymorphism associated with IL28B in chronic hepatitis C patients. Scand J Gastroenterol. 2011; 46: 955-961.

43. Aoki YH, Ohkoshi S, Yamagiwa S, et al. Characterization of elevated alanine amino transferase levels during pegylated-interferon $a-2 b$ plus ribavirin treatment for chronic hepatitis C. Hepatol Res. 2011; 41: 118-125.

44. Kanda T, Yokosuka O, Imazeki F, Yokosuka O. Acute hepatitis C virus infection, 1986-2001: a rare cause of fulminant hepatitis in Chiba, Japan. Hepatogastroenterology. 2004; 51: 556-558.

45. Read AE, Donegan E, Lake $\mathrm{J}$, et al. Hepatitis $\mathrm{C}$ in patients undergoing liver transplantation. Ann Intern Med. 1991; 114: 282-284. 